\title{
The Environmental Context as a Driver for Diversity Effects on Litter Decomposition ${ }^{\dagger}$
}

\author{
André Yuri Belo *, Mery Alencar, Adriano Soares Mota, Adriano Caliman \\ * Correspondence: andreyurispb@gmail.com \\ + Presented at the 1st International Electronic Conference on Biological Diversity, Ecology and Evolution, \\ 15-31 March 2021; Available online: https://bdee2021.sciforum.net/ (accessed on).
}

Citation: André Yuri Belo *, Mery Alencar, Adriano Soares Mota, Adriano Caliman. The Environmental Context as a Driver for Diversity Effects on Litter Decomposition. 2021, 5, x. https://doi.org/10.3390/xxxxx

Publisher's Note: MDPI stays neutral with regard to jurisdictional claims in published maps and institutional affiliations.

Copyright: (c) 2021 by the authors. Submitted for possible open access publication under the terms and conditions of the Creative Commons Attribution (CC BY) license (http://creativecommons.org/licenses/by/4.0/).

\begin{abstract}
Studies from the past two decades indicate the important role of functional diversity and litter identity as a determining factor in decomposition. So far, researchers have search to understand the effects of litter diversity in opposite environmental contexts, in which the abiotic pathway prevails over the biotic pathway. We search to test the effects of the functional diversity of litter on decomposition in areas under vegetation (i.e., more favorable to biological decomposition), and in areas exposed to the sun (i. e., more favorable to photodegradation), prioritizing the litter functional diversity. We used an experimental approach in situ with litterbags in two different environmental contexts in a rainforest in RN, Brazil. We used four species with different specific leaf areas (SLA) and put in mono and bicultures, totaling 120 litterbags, placing 60 of them in the most exposed to the sun and the rest in the shaded environment. We observed that the decomposition rate in habitats with greater exposure to photodegradation was on average $34 \%$ higher than that observed in habitats with vegetation. There were also effects of diversity in some treatments, indicating the effect of functional identity, in which combinations of litter leaf with greater differences in SLA values (i. e., discrepant bicultures) showed a slower decomposition in bicultures than in the corresponding monocultures. With the predictions of climate change, regions such as rainforest can become increasingly arid, so our work suggests that in these environments the high rate of photodegradation can accelerate the decomposition of the litter with high SLA, With the predictions of climate change, certain regions such as rainforest can become increasingly arid, so our work suggests that in these environments the high rate of photodegradation can accelerate the decomposition of the litter with high SLA, besides, to retard leaf litter decomposition of species with discrepant SLA's.
\end{abstract}

Keywords: Specific Leaf Area (SLA); photodegradation; functional diversity; functional identity 